\title{
POLITICAS PUBLICAS PARA A EDUCAÇÃO INCLUSIVA: UMA ANÁLISE SOBRE OS INSTRUMENTOS FORMATIVOS DA PRATICA DOCENTE NOS ANOS INICIAIS, NO CONTEXTO EDUCACIONAL DE BAIÃO/PA, NO ANO DE 2018.
}

Cloves Nazaré Pimentel*

\section{RESUMO}

Neste trabalho buscou-se analisar as políticas pública para a Educação Inclusiva dos alunos com Necessidades educativas especiais e com deficiências, no Ensino Fundamental anos Iniciais (1ํ ao $5^{\circ}$ ano) e sua implementação através dos instrumentos formativos da pratica docente no contexto educacional de Baião, no ano de 2018. A metodologia utilizada foi de natureza quantitativa, tendo o enfoque quantitativo, direcionado pelo alcance exploratório Analítico. Com desenho não experimental, ex-post-facto. O estudo teve os seguintes objetivos: Evidenciar as políticas pública para a educação inclusiva e suas contribuições para a inclusão dos alunos com Necessidades educativas especiais e com deficiências no ensino Fundamental (anos iniciais) no ambiente escolar; verificar como se dá implementação da política pública para inclusão através dos instrumentos formativos no Ensino Fundamental no contexto escolar. Especificar como a pratica docente vem promovendo a inclusão no Ensino Fundamental no contexto educacional. Sobre os resultados evidenciou-se que as políticas públicas para a educação inclusiva, são existenciais no espaço escolar, porém muitas são as falhas neste processo, pois matricular a pessoa com deficiência na escola não garante a ela ter seus direitos educacionais assistidos. A pesquisa foi direcionada pelas seguintes hipóteses: Hipótese investigativa afirmativa as políticas públicas para a educação inclusiva dos alunos com Necessidades educativas especiais e com deficiências, são relevantes nos anos iniciais sendo implementada de maneira positiva através dos instrumentos formativos da pratica docente no contexto educacional de Baião, no ano de 2018. Já a hipótese Investigativa nula destaca que as políticas públicas para a educação inclusiva dos alunos com Necessidades educativas especiais e com deficiências, não são relevantes nos anos iniciais não sendo implementada de maneira positiva através dos instrumentos formativos da pratica docente no contexto educacional de Baião, no ano de 2018.

*Cloves Nazaré Pimentel, licenciado pleno em pedagogia pela Ufpa, pós graduação em educação Infantil pela Uepa, Especialização em Gestão de Projetos pela Cesupa. Professor da rede estadual e técnico da SEMED/ Baião. Email: Clovespimentel@hotmail.com 
Palavras-chave: Políticas públicas para educação inclusiva. instrumento formativo, Pratica, Pedagogia.

\section{ABSTRACT}

This work sought to analyze the public policies for the inclusive education of students with special educational needs and with disabilities, in the elementary school years (1st to 5th year) and its implementation through the formative instruments of teaching practice in the educational context of Baião in the year 2018. The methodology used was of a quantitative nature, having the quantitative approach, guided by the exploratory scope Analytical. With no experimental design, ex-post facto. The study had the following objectives: Evidence of public policies for inclusive education and its contribution to the inclusion of students with special educational needs and deficiencies in early childhood education and elementary school (initial years) school environment; To verify how the public policy is implemented for inclusion through the formative instruments in children's education and fundamental education in the school context. Specify how the teaching practice has promoted inclusion in early childhood education and fundamental education in the educational context. The results showed that public policies for inclusive education are existential in the school space, but many fail in this process, as enrolling the disabled person in school does not guarantee that they have their educational rights assisted. The research was guided by the following hypotheses: Affirmative research hypothesis policies published for inclusive education of students with special educational needs and disabilities are relevant in the initial years and is implemented in a positive way through the training instruments of teaching practice in the educational context of Baião, in the year 2018. The null Investigative hypothesis emphasizes that the policies published for the inclusive education of students with special educational needs and with disabilities are not relevant in the years was not implemented in a positive way through the training instruments of the teaching practice in the educational context of Baião, in the year 2018.

Keywords: Public policies for inclusive education. Formative instrument. Practice, Pedagogy. 


\section{INTRODUÇÃO}

O processo de ensino e aprendizagem dentro da perspectiva da educação inclusiva, para alunos com Necessidades Educativas Especiais são desafios que estão postos a todos os sistemas públicos de ensino de nosso País, em todos os níveis de ensino e aos professores de um modo geral, principalmente a partir da implementação de um conjunto de leis que regulamentam a educação especial atualmente e que tem ganhado notoriedade e se intensificado mais recentemente através dos documentos que tratam da Política Nacional de Educação Especial na Perspectiva da Educação Inclusiva.

Pois, é notório, que nas últimas décadas têm ocorrido mudanças significativas acerca da educação especial e das políticas públicas de educação inclusiva no Brasil que, expressam-se através das legislações vigentes, tais como: A Lei de Diretrizes e Bases da Educação Nacional de 1996. E, na sucessão de dispositivos normativos, resoluções, 02/2001 CNE/CEB (BRASIL, 2001), Resolução 04/2009 do CNE/CEB (BRASIL, 2009) e o Plano Nacional de Educação (2014). Tais mudanças têm evidenciado a necessidade de reafirmar as políticas de educação especial e inclusiva como marco legal e constitucional devendo ser oferecida em todos os níveis e modalidades educacionais dos sistemas públicos de ensino, contribuindo desta forma para a superação de sistemas educacionais de segregação de escolarização dos alunos com deficiência, e necessidades educativas especiais, paralelas a instituição de serviços que possam oferecer e assegurar os processos de inclusão.

A escolha da temática: Políticas Públicas para a Educação Inclusiva: Uma análise sobre os instrumentos formativos da pratica docente nos anos iniciais no contexto educacional de Baião, no ano de 2018, objeto de estudo desta pesquisa, não surgiu, por acaso, mas, ao contrário, é resultante das experiências como técnico pedagógico da Secretaria Municipal de Educação de Baião, e dos constantes desabafos e angústias dos professores que atuam com este nível de ensino Educação Infantil e Ensino Fundamental (anos iniciais), da rede municipal acerca das dificuldades encontradas para trabalhar com os alunos que apresentam necessidades educativas especiais, como decorrência direta da ausência de políticas públicas educacionais desenvolvidas por esta secretaria, destinadas a 
oferta e promoção da educação inclusiva aos alunos portadores de Necessidades educativas especiais, que estão regularmente matriculados nestes níveis em classes comuns; de formação continuada aos docentes, e de carência de metodologias e recursos didáticos que possam subsidiar suas práticas pedagógicas.

A referida pesquisa se propõe a realizar um estudo investigativo tendo como interrogante central "De que maneira as Políticas Públicas para a educação inclusiva são implementadas no âmbito escolar direcionando os instrumentos formativos para orientação da prática docente na educação de Baião no ano de 2018 ?

A pesquisa ocorreu no contexto do Município de Baião, o referido Município fica localizado na Mesorregião nordeste paraense e microrregião de Cametá. Possui uma área de $3.758,273 \mathrm{~km}$ e uma população estimada em torno de 44.956 habitantes de acordo com o censo do IBGE (fonte IBGE: 2016), e está distante cerca de 260 km em relação à capital do Estado do Pará (Belém).

Em relação à educação, o Sistema Educacional de Baião, atua com os seguintes níveis de ensino: Educação infantil que atende crianças de 03 a 05 anos (em maternal II, Jardim I e Jardim II), Ensino Fundamental (anos iniciais e Finais), e a Educação de Jovens e Adultos - EJA - no Ensino Fundamental e com Educação Especial. Atualmente de acordo com dados do Censo Escolar/2017, o Município possui cerca de nove mil cento e quarenta e sete (9.147) alunos matriculados, estando assim distribuídos:

\begin{tabular}{l|c|c|c|c|}
\hline \multicolumn{1}{|c|}{$\begin{array}{c}\text { Alunos } \\
\text { Modalidade de ensino }\end{array}$} & matriculados & Área urbana & Área rural \\
\cline { 2 - 4 } & Educqção infantil & 1.738 & 641 & 1.097 \\
Ensin & 3.728 & 1.320 & 2.408 \\
Ensiino Fundamental (ano iniciais). & 2.825 & 1.199 & 1.626 \\
Eduqação de Jovens e Adultos - EJA & 751 & 222 & 529 \\
Eduqaecão Espeeial & 105 & 71 & 34 \\
\hline TOTAL & 9.147 & 3.453 & 5.694 \\
\hline
\end{tabular}

\section{Fonte: Censo Escolar/2017/SEMED /Baião.}

Neste entendimento, o referido estudo pretende realizar um trabalho investigativo partir de uma abordagem quantitativa, das Políticas Públicas de Educação especial e Inclusiva, á nível de educação brasileira, tendo como embasamento teórico, desta análise, as políticas públicas educacionais contidas nos marcos legais, que asseguram o direito a educação para todos e o respeito ás diferenças tais como: Declaração Universal dos Direitos Humanos, Declaração de Salamanca, 
Constituição Brasileira, Estatuto da Criança e Adolescente, Lei de Diretrizes e Bases da Educação (lei no 9394/96), e dos Documentos que tratam da Política Nacional de Educação Especial na Perspectiva da Inclusão (Brasil, MEC.SEESP, 2008).

Concomitante ao marco legal contido nas legislações vigentes, acima descritos, a referida pesquisa terá como fio condutor deste trabalho, um estudo das metas e diretrizes contidas no I Plano Municipal de Educação (versão/2008), no II Plano Municipal de Educação (versão 2013) e mais recentemente o III Plano Municipal de Educação (versão/2016), a fim de que, mediante análise destes documentos, a fim de identificar instrumentos que assegure a inclusão escolar e a formação docente dos sujeitos envolvidos no processo formativo escolar das instituições municipais de ensino e dos atores participantes desta pesquisa.

\title{
POLÍTICAS PÚBLICAS PARA A EDUCAÇÃO INCLUSIVA: O CONTEXTO HISTÓRICO INTERNACIONAL DAS POLÍTICAS EDUCACIONAIS.
}

No contexto de sociedade atual, cada vez mais, exige-se que as políticas públicas educacionais possam assegurar a garantia de direitos humanos a uma parcela cada vez maior da sociedade, estando atrelada a uma concepção mais ampla de direitos. E essa garantia de direitos, estão presentes nos diversos documentos internacionais que tratam das políticas educacionais surgidos ao longo de todo um contexto histórico das sociedades, e que visam acima de tudo, assegurar a garantia do direito ao ensino público a uma parcela significativa da população mundial.

Neste sentindo, para SANTOS,

\begin{abstract}
A concepção contemporânea apresenta os direitos humanos com uma visão integral, interligando de maneira indivisível os direitos civis e políticos aos direitos sociais, econômicos e culturais. Essa integração de direitos assegura a existência de cada um deles pela efetivação integral dos direitos e da liberdade fundamental, caracterizando-se pelos processos de universalização e internacionalização dos direitos (2011, p.37).
\end{abstract}

Neste entendimento, os direitos humanos devem convergir e atingir uma visão holística do homem, em seus diferentes aspectos da vida social, cultural, política e econômica, o que pressupõem um processo de uma integralização desses direitos, não podendo limitar sua atuação, apenas as conquista no campo educacional, pois de acordo com a visão de Santos (2011, p. 46), no contexto da economia e da 
política, os direitos humanos surgem para garantir o direito de todos a serem incluídos na escola comum pela efetivação integral desses direitos.

Assim, segundo SANTOS,

A educação envolve uma amplitude de possibilidades e tem sido utilizada como meio de influência e determinação social. Devem ser de interesse social o desempenho do papel pedagógico e político nas escolas, para que todos tenham compreensão do dever do Estado e da família; e dessa relação, do direito de participar da escola, poder desenvolver suas potencialidades: o direito à educação. A discussão da construção da educação inclusiva inserida na concepção de direitos humanos é internacional, envolvendo todos os alunos, que devem receber ensino e aprendizagem juntos na sala de aula comum. (2011, p.37)

Os direitos humanos devem estar postos a serviço de uma política libertária e emancipatória, onde a igualdade de direitos nas políticas públicas deve ser a busca fundamental do homem, por autonomia e reconhecimento de sua identidade pessoal e social na comunidade local e regional. Pois, cada sujeito é universal em suas peculiaridades e diferenças, é o que afirma MANTOAN:

\begin{abstract}
Quando entendemos que não é a universalidade da espécie que define um sujeito, mas as suas peculiaridades, ligadas a sexo, etnia, origem, crenças, tratar as pessoas diferentemente pode enfatizar suas diferenças, assim como tratar igualmente os diferentes pode esconder as suas especificidades e excluí-los do mesmo modo: portanto, ser gente é correr sempre o risco de ser diferente (MANTOAN, 2005, p. 17).
\end{abstract}

A partir de então, na dinâmica do tecido social, o indivíduo com necessidades educativas especiais ou deficiências passa a ser visto em sua individualidade, e em função de suas especificidades e características peculiares à sua condição. A esse sujeito de direito lhe é assegurado um tratamento especial, o direito e o respeito à diferença, à diversidade. Assim:

O processo de universalização dos direitos humanos permitiu a formação de um sistema internacional de proteção desses direitos. Esse sistema é integrado por tratados internacionais de proteção que refletem, sobretudo, a consciência ética contemporânea compartilhada pelos Estados, na medida em que invocam o consenso internacional acerca de parâmetros protetivos mínimos relativos aos direitos humanos (PIOVESAN, 2006, p. 1)

As mudanças propaladas pelos direitos humanos solicitam dos Estados e governos à normatização e a efetivação de programas e políticas públicas nacionais que 
assegurem a efetivação e universalização desses direitos, o que implica levar em consideração a dimensão globalizada da atual economia dos países e estados.

Sobre este aspecto, SANTOS afirma que,

Com a tendência mundial de efetivação da concepção inclusiva, em 1994, a Declaração de Salamanca é a representação de lutas dos movimentos em favor dos direitos humanos, sendo reconhecida como um dos documentos símbolo da inclusão social que vai surtir efeitos na educação. Assim, também nesta década, por meio da Declaração Universal de Direitos Humanos e a Declaração Mundial sobre Educação para Todos, configuram-se reformas estruturais e educacionais significativas para as lutas dos grupos excluídos no Brasil (2011, p.48)

A Declaração trata dos princípios, da política e da prática em educação inclusiva, defendendo uma escola inclusiva, que possibilite a crianças o direito de aprender e vivenciar a solidariedade na relação entre as necessidades educacionais especiais e os outros educandos sem necessidades especiais, a partir de um ambiente favorável à diversidade, à solidariedade, à igualdade, à alteridade e à participação da pessoa com deficiência.

Nesse sentido,

O desafio que confronta a escola inclusiva é no que diz respeito ao desenvolvimento de uma pedagogia centrada na criança e capaz de bem sucedidamente educar todas as crianças, incluindo aquelas que possuam desvantagens severas. O mérito de tais escolas não reside somente no fato de que elas sejam capazes de prover uma educação de alta qualidade a todas as crianças: o estabelecimento de tais escolas é um passo crucial no sentido de modificar atitudes discriminatórias, de criar comunidades acolhedoras e de desenvolver uma sociedade inclusiva (UNESCO, 1994, p. 4).

Existem outros documentos internacionais que abordam os direitos universais e discutem a temática da inclusão no contexto do ensino regular tais como: Declaração

Universal dos Humanos, Declaração Mundial de Educação para Todos e Declaração de Salamanca que trataremos a seguir.

\subsubsection{Os direitos universais do ser humano}

Os direitos humanos são preceitos universais, assegurados na Declaração Universal dos Direitos Humanos (Adotada e proclamada pela resolução 217 A (III) da Assembleia Geral das Nações Unidas em 10 de dezembro de 1948), e segundo 
Leme (2011, p.37) retrata, de certo modo, a repulsa da sociedade no tocante às barbáries históricas cometidas contra os povos.

Portanto, a Declaração Universal dos Direitos Humanos, surge

Neste sentido, segundo SANTOS,

Esse documento tem como premissa a educação como um direito objetivo para a obtenção da ordem e segurança nas relações sociais e educacionais, sendo a educação um direito a todos os cidadãos, e sendo dever do Estado fazer com que esse direito seja protegido e efetivado. (2011, p.49).

Estando assegurado em seu Art. 26 da Declaração Universal dos Direitos Humanos, que estabelece:

1.Toda pessoa tem direito à instrução. A instrução será gratuita, pelo menos nos graus elementares e fundamentais. A instrução elementar será obrigatória. [...].

2.A instrução será orientada no sentido do pleno desenvolvimento da personalidade humana e do fortalecimento do respeito pelos direitos humanos e pelas liberdades fundamentais. A instrução promoverá a compreensão, a tolerância e a amizade entre todas as nações e grupos raciais ou religiosos, e coadjuvará as atividades das Nações Unidas em prol da manutenção da paz (UNESCO, 1948).

Esta declaração é composta por 30 artigos que, estimulam acordos, tratados e convenções, além de fundamentarem o direito internacional relativo aos direitos humanos.

Dentre os artigos que o compõem destacamos dois, por tratarem da igualdade e da educação.

São eles, respectivamente:

Artigo I - Todos os homens nascem livres e iguais em dignidade e direitos. São dotados de razão e consciência e devem agir em relação uns aos outros com espírito de fraternidade.

Artigo XXVI - I) Todo o homem tem direito à instrução. A instrução será gratuita, pelo menos nos graus elementares e fundamentais. A instrução elementar será obrigatória. A instrução técnica e profissional será acessível a todos, bem como a instrução superior, está baseada no mérito.

II)A instrução será orientada no sentido do pleno desenvolvimento da personalidade humana e do fortalecimento do respeito pelos direitos do homem e pelas liberdades fundamentais. A instrução promoverá a compreensão, a tolerância e amizade entre todas as nações e grupos raciais ou religiosos, e coadjuvará as atividades das Nações Unidas em prol da manutenção da paz.

III)Os pais têm prioridade de direito na escolha do gênero de instrução que será ministrada a seus filhos. 
Neste sentido, segundo LEME (2011, p.38), a Declaração, representa uma conquista em termos de políticas sociais, já que ressaltou o valor da solidariedade (fraternidade) e modificou a compreensão do direito à igualdade no sentido material, contra a desigualdade social.

No âmbito educacional, para SANTOS (2011, p.39), ao declarar que "todos os homens nascem livres e iguais em dignidade e direitos" (art. I), insere a dignidade no contexto da igualdade. Assim, a relação de igualdade é reconhecida como dever do Estado. Deste modo, cria-se as condições para a isonomia de oportunidades, além de reconhecer a solidariedade como valor universal. Sendo este o grande avanço dos Direitos Humanos (1948), trazer à cena a responsabilidade do Estado no que tange à desigualdade social.

Em relação ao exposto, (SANTOS, 2011 p.42), afirma que,

\begin{abstract}
A concepção de direitos humanos na contemporaneidade está fundamentada no princípio maior da igualdade, da dignidade humana, sendo estes os direitos civis, políticos, sociais, econômicos e culturais, isto é, autênticos e verdadeiros acionáveis direitos fundamentais. Neste campo de reconhecimento em que todo cidadão é um sujeito de direitos, a tônica do papel do Estado passa a se configurar como agente da garantia dos direitos.
\end{abstract}

Assim, a garantia dos direitos humanos universalmente prescritos em tratados assume um caráter político, onde sua efetivação e implementação está condicionada a diversos fatores e a atuação organizada dos diferentes agentes envolvidos neste processo (Estado x Sociedade Civil).

\title{
DECLARAÇÃO MUNDIAL DE EDUCAÇÃO PARA TODOS:
}

Esta declaração surge da necessidade de se assegurar a todos os indivíduos, a garantia da universalização do acesso à educação em todos os níveis e modalidades da educação escolar e possibilitar a permanência de todos na escola em igualdade de condições e oportunidades. Pois, para LEME,

A educação para todos representa a conquista dos direitos humanos e o princípio da igualdade, formando, com esses, o conjunto que está na base da inclusão em educação. Deste modo, a inclusão expressa um objetivo a ser alcançado que busca garantir a igualdade de oportunidades, o respeito à diversidade e a paz entre os povos (2011, p.34). 
Assim essas ações se intensificaram no cenário internacional através da Conferência Mundial sobre Educação para Todos, realizada em Jomtien, na Tailândia, de 5 a 9 de março de 1990. Coordenada pelo UNESCO e o Banco Mundial, onde saíram os documentos sobre a Declaração Mundial de Educação para Todos. Tendo como alvo os países com índices precários de escolarização, com foco na Educação Básica; da qual o Brasil encontra-se inserido nessa realidade.

A Declaração Mundial sobre Educação para Todos e o Marco de Ação para a Satisfação das Necessidades Básicas de Aprendizagem são documentos resultantes da conferência realizada em Jomtien, em 1990. Ambos compõem o mesmo documento, sendo dez artigos referentes à Declaração e sete postos-chave de delineamento do Plano de Ação: introdução, objetivos e metas, princípios de ação, ação prioritária em nível nacional, ação prioritária ao nível regional (continental, subcontinental e intercontinental), ação prioritária em nível mundial e calendário indicativo de implementação para os anos 90.

Assim, a educação básica ficou no centro das atenções quando, em 1990, o país passa a integrar o mundo globalizado, exigindo investimento na melhoria educacional do Brasil, para que o desenvolvimento pudesse acontecer. Diante disso, há o comprometimento internacional do País, objetivando o oferecimento de uma educação básica de qualidade para todas as faixas etárias - crianças, jovens e adultos - com financiamento da UNESCO e do Banco Mundial. Esse momento foi considerado como um dos marcos de debates e discussões das modificações para que uma proposta de educação inclusiva pudesse ser efetivada.

O documento foi assinado pelos 155 governos presentes que se comprometeram a garantir "uma educação básica de qualidade" para crianças, jovens e adultos no prazo de dez anos, ou seja, até o ano 200019, sob o pressuposto de que este nível de ensino seria satisfatório às necessidades básicas de aprendizagem.

$\mathrm{Na}$ Conferência, a pauta em discussão teve como pilar três pontos fundamentais: o acesso à educação básica, o dever da sociedade de incentivá-lo e a busca por parâmetros adequados para o estabelecimento de compromissos amplos, em termos de políticas internacionais. Este objetivo foi reforçado pela emergência de se reverter o quadro crítico em que a educação se encontrava, na época, 


\begin{abstract}
Mais de 100 milhões de crianças, das quais pelo menos 60 milhões são meninas, não têm acesso ao ensino primário; mais de 960 milhões de adultos - dois terços dos quais mulheres são analfabetos, e o analfabetismo funcional é um problema significativo em todos os países industrializados ou em desenvolvimento; mais de um terço dos adultos do mundo não têm acesso ao conhecimento impresso, às novas habilidades e tecnologias, que poderiam melhorar a qualidade de vida e ajudá-los a perceber e a adaptar-se às mudanças sociais e culturais; e mais de 100 milhões de crianças e incontáveis adultos não conseguem concluir o ciclo básico, e outros milhões, apesar de concluí-lo, não conseguem adquirir conhecimentos e habilidades essenciais (UNESCO, 1990, Preâmbulo).
\end{abstract}

Diante desta constatação, propôs-se a luta pela revalorização da educação básica, tendo em vista que, a educação pode contribuir para conquistar a paz e a solidariedade internacional, pela possibilidade de "contribuir para conquistar um mundo mais seguro, mais sadio, mais próspero e ambientalmente mais puro, e que, ao mesmo tempo, favoreça o progresso social, econômico e cultural, a tolerância e a cooperação internacional" (UNESCO, 1990, p. 2).

A universalização da educação básica, por meio da Educação para Todos, é caracterizada como um dos meios de se alcançar o direito à educação e, consequentemente, de se promover a inclusão em educação. Diante disso, pretendemos verificar como o conceito de educação foi trabalhado pelos organismos internacionais na Conferência de Jomtien e com isso discutir o viés de inclusão em educação anunciada pela mesma:

\begin{abstract}
Educação para todos significa assegurar que todas as crianças tenham acesso a uma educação básica de qualidade. Isto implica criar condições nas escolas e nos programas da educação básica que possibilitem a aprendizagem de todas as crianças com mais ou menos capacidades. Essas condições devem proporcionar um ambiente inclusivo, eficaz para as crianças, simpático e acolhedor, saudável e protetor. O desenvolvimento desse ambiente amigável de aprendizagem é uma parte essencial dos esforços de todos os países do mundo para melhorar a qualidade e desenvolver o acesso às suas escolas (UNESCO, 2005, p.7).
\end{abstract}

Deste modo, a "educação para todos" entra em cena com propósitos amplos, cuja grandeza já se verifica no próprio título, "Educação para Todos", que de forma impactante gera nos sujeitos sentimento de pertencimento ao sistema educacional assim como uma suposta afirmação na sociedade.

Nesse sentido, para Leme, a Declaração de Jomtien, assume a perspectiva do "direito à educação, como direito fundamental de todos", em consonância com a Declaração dos Direitos Humanos (1948). (2011, p.50). 
Ainda assim, a Educação para Todos deu um passo significativo ao reconhecer que todos (crianças, jovens e adultos) têm necessidades básicas de aprendizagem para resolver, sendo essas entendidas de modo amplo:

A possibilidade de que a expansão das oportunidades educativas se traduza em
um desenvolvimento significativo de cada pessoa ou da sociedade depende, em
última instância, de que as pessoas realmente aprendam como resultado dessas
oportunidades, isto é, que adquiram conhecimentos úteis, capacidade de
raciocínio, aptidões e valores. Como consequência, a educação básica deve
centrar-se na aquisição e nos resultados efetivos da aprendizagem, em vez de
prestar atenção exclusiva na matrícula, na participação contínua em programas
organizados e na realização das exigências necessárias para a obtenção de um
certificado. A adoção de enfoques ativos e participativos é de especial importância
para garantir a aprendizagem e permitir que aqueles que aprendam desenvolvam
todo seu potencial. Por isso, é necessário definir níveis aceitáveis de
aprendizagem dentro dos programas educativos, "assim como melhorar e aplicar
sistemas de avaliação de resultados de aprendizagem" (UNESCO, 1990, Artigo 4).

Segundo LEME,

O viés de participação defendido na declaração também contempla a participação popular nos processos decisórios rumo a uma política educacional democrática. Nesse sentido, incentiva as alianças entre profissionais de educação, famílias, comunidades locais e órgãos governamentais como forma viabilizadora de planejamento, implementação, administração e avaliação dos programas de educação básica. Este ideal democrático de participação consta entre seus princípios de ação (2011, p.51).

O processo de inclusão não pode ser direcionado como responsabilidade somente da escola, pois a inclusão necessita ser posta em pratica havendo a participação e todos, que cada segmento da sociedade reconheça seu papel, seja como agente fiscalizador ou promovedor da inclusão. A escola nesse sentido necessita chamar a responsabilidade para atuar em parceria a suas ações para que a inclusão seja um direito assistido seja no âmbito escolar ou social.

Por serem as necessidades básicas de aprendizagem complexas e diversas, sua satisfação requer ações e estratégias multissetoriais que sejam parte integrante dos esforços de desenvolvimento global. Se, mais uma vez, a educação básica for considerada como responsabilidade de toda a sociedade, muitos parceiros deverão unir-se às autoridades educacionais, aos educadores e a outros trabalhadores da área educacional, para o seu desenvolvimento. Isso implica que uma ampla gama de colaboradores - 
famílias, professores, comunidades, empresas privadas (inclusive as da área de informação e comunicação), organizações governamentais e não governamentais, instituições, etc. - participe ativamente na planificação, gestão e avaliação das inúmeras formas assumidas pela educação básica (UNESCO, 1990, p.18).

Levar a cabo a Educação para Todos implica instaurar políticas multissetoriais capazes de enfrentar de maneira coordenada alguns fatores que incidem na educação e comprometem a possibilidade de aprender, como a pobreza, a desnutrição, desemprego, entre outras, que assolam a sociedade em seu conjunto. (Leme, 2011, p.52).

O Brasil acatou a Declaração Mundial sobre Educação para Todos (UNESCO, 1990). Isso significa, de modo geral, o compromisso do nosso governo perante à comunidade internacional de erradicar o analfabetismo e universalizar o ensino fundamental no país. Cumpre ressaltar que tem se tornado tradição a afirmação do compromisso brasileiro nas políticas internacionais de educação, o que configura uma forte adesão às mesmas. (Leme, 2011, p.52).

\section{INSTRUMENTOS FORMATIVOS}

As políticas educacionais de inclusão promovem a garantia a pessoa com deficiência de ter direito em ambiente escolar nas turmas regulares de ensino, dar direito ao aluno com deficiência de ter uma educação de qualidade que respeite suas limitações e promova sua aprendizagem, integração e socialização junto aos demais alunos foi uma conquista árdua, porém, a luta ainda continua, pois fiscalizar essas políticas se faz urgente e necessário, no Brasil a inclusão mesmo sendo um dispositivo amparado legalmente, ainda fica muito restrito a direitos constituintes garantidos em um papel.

A comunidade educacional como a própria sociedade precisa agir como agentes fiscalizadores desses dispositivos legais, pois o aluno com deficiência necessita ser incluso de fato e direto e não somente inserido como ocorrer nas maiorias das unidades de ensino, em que através da matricula o aluno com deficiência chega à sala de aula, porém, talvez essa seja a maior exclusão vivenciada nos últimos anos, inserir não poderá nunca ser sinônimo de incluir. 
O aluno com deficiência chega ao ambiente escolar e se depara com rampas que não atende suas necessidades, de locomoção por terem sido construídas de qualquer formar, daí a necessidade de os concelhos agirem como agente fiscalizadores, junto a própria família, as escolas não estão adaptadas para receber os alunos com deficiências, seja nas questões físicas estruturais, pedagógicas, metodológicas. A ausência de recursos adaptados ou apropriados nas escolas públicas para garantira ao aluno com deficiência um ensino aprendizagem de qualidade, é uma grande realidade.

A falta de políticas formativas continuadas e especificas para os educadores, no ambiente escolar é outra problemática que contribui para que ocorra na escola a inserção em vez da inclusão. A maioria dos docentes em ambiente de sala de aula com alunos inseridos não conseguem promover a inclusão por falta de conhecimento em ressignificar sua pratica para direcionar a sua classe novas metodologias de ensino ou metodologias adaptadas para atender as necessidades do aluno. O que observamos são formações fragmentadas que acabam não alcançando a necessidade dos docentes, formações estas que não são continuadas. Outro fator é a o docente receber uma formação para inclusão por ter um aluno com deficiência, porém os instrumentos formativos deveriam ser direcionados a escola como um todo, pois o aluno muda de turma e nem sempre o professor que recebeu a formação acompanha a turma onde este aluno será incluído.

As escolas necessitam de formações inclusivas emergenciais para os professores, pois estes se sentem muitas vezes fracassados e desestimulados por não conseguirem atender a necessidade de seus alunos.

A necessidade de promover no ambiente escolar politicas formativas para alunos com deficiências, especificas, como, deficiência visual e baixa visão severa, em que a escola por lei necessita ter metodologias e recursos adaptados para assessora a aprendizagem desses alunos, ensino de braile, Lupa, maquinas especificas para ampliação, papeis especiais, assim as metodologias assistivas com uso de recurso tecnológicos especiais para este tipo de deficiência necessitam ser uma ação real no ambiente escolar.

Cita-se ainda a deficiência auditiva, em que se exige o uso da linguagem de sinais, a escola necessita promover o uso de instrumento formativo para atender a rede de ensino, mais o que vemos é um professor ser chamado para aprender a linguagem de sinais, quando na verdade essa política formativa precisa ser direcionada a todos 
os sujeitos escolares dos alunos ao porteiro, além de materiais e recursos como jogos adaptados para assessorar a pratica docente.

Destacam-se as deficiências múltiplas física, provocada pela paralisia, ou outro problema, as restrições neurológicas, as síndromes como autismo, síndrome de Down, asperge, em fim entre muitas outras deficiências e limitações que precisam ser compreendidas para poder ser assistidas no espaço escolar.

A inclusão só será uma garantia assistida quando os dispositivos legais forem postos e pratica. O aluno com deficiência possui limitações que necessitam ser respeitadas, dificuldades que necessitam ser acompanhadas e potencialidades que necessitam ser incentivadas.

A escola necessita de profissionais especializados para assessora tanto o aluno com deficiência como o docente, pois o professor compreende das ações pedagógicas, mais há a necessidade de outros acompanhamentos para assistir tanto a pratica como o processo e aprendizagem desse aluno. A presença de uma equipe especializada é garantida pelos dispositivos legais inclusivos, como assistente social, fonoaudiólogo, psicopedagogo, neuro psicopedagogo, psicólogo. Além de acompanhamento com os profissionais que atendem a área patológica. $A$ inclusão só será efetivada na pratica se as mudanças ocorrem seja no campo pedagógico, estrutural, administrativo, gestor, e principalmente formativo.

\section{AS FORMAÇÕES CONTINUADAS E A INCLUSÃO AVANÇOS E DESAFIOS.}

São muitas as mudanças ocorridas no campo da educação, e entre essas destacase as mudanças no campo da Educação especial, que ao longo da história da educação brasileira, deixa sua marca para registrar e garantir o direito das pessoas com deficiências que por muito anos foi renegado. As lutas pela escola inclusiva maram o campo da educação, pois para efetivação da inclusão, ou seja, garantir a permanecia da pessoa com deficiência nas turmas regulares de ensino foi preciso muito mais que dar a essas pessoas sua matricula no espaço escolar.

O grande desafio da inclusão direciona mudanças em todo o contexto educativo, inserir a pessoa com deficiência no campo educacional não garante a ela a inclusão. A necessidade formativa para os profissionais do campo escolar é uma necessidade urgente e necessária, pois essa é uma enorme problemática enfrentada nas escolas até hoje. 
Os docentes recebem o aluno com deficiência na sala de aula sem ter conhecimento suficiente para atender suas necessidades. Os cursos de capacitação ou formação continuada muitas vezes são muito superficiais e não atendem as necessidades dos professores, ou ainda ocorrem em um curto prazo de tempo.

Outra fragilidade em termo da formação para os profissionais da educação em termo da inclusão é que as capacitações na maioria das vezes não são direcionadas a todos os profissionais da rede, geralmente são escolhidos os profissionais que participam das formações. Por estar naquele momento com aluno em sala, esse é um grande erro, pois os profissionais mudam de turma, e os alunos também, assim as formações deveriam ser direcionadas a todos os profissionais.

A inclusão deveria ser o elemento primordial para combater a exclusão porem ainda vivenciou em muitos aspectos uma escola que insere a pessoa com deficiência e exclui Ela do verdadeiro sentido da inclusão.

As dificuldades vão além da necessidade de dispositivos formativos, perpassam pela adaptação da estrutura física, da acessibilidade de espaço, de materiais, de formação, de fiscalização. Para que a escola seja de fato um espaço inclusivo.

Por muito tempo as pessoas com deficiências eram assistidas educacionalmente em espaço diferenciados dos demais alunos ditos normais. Com a inclusão a escola necessita está apta a tender as necessidades das pessoas com deficiências.

Uma política de formação de professores é um dos pilares para a construção da inclusão escolar, pois a mudança requer um potencial instalado, em termos de recursos humanos, em condições de trabalho para que possa ser posta em prática.

(MENDES, 2004, p. 227)

Os alunos com deficiências necessitam está em sala de aula participando das atividades de classe para isso os profissionais da educação precisaram adaptar as metodologias de ensino para atender os reais interesses e necessidades dos alunos com deficiências respeitando assim suas limitações. Assim a escola necessita está preparada para receber os alunos inclusos respeitando suas características e limitações sendo uma instituição educativa que deve ser de uso de todos.

As políticas públicas inclusivas garantem o direito da inclusão para que não haja mais crianças com deficiência fora da escola ou segregados em espaço diferenciados das turmas regulares de ensino. O direito de conviver interagir e integra-se é constitui-te da pessoa com deficiência. 
O princípio fundamental desta política é de que o sistema regular deve atender a diversidade do alunado, isto é, todos os que se encontram excluídos, frequentadores da escola. Este atendimento inclui, necessariamente, $\mathrm{O}$ atendimento dos alunos considerados deficientes, tanto físicos, visuais, auditivos e mentais na escola regular (BRASIL, 2001).

É como observarmos as dificuldades que os docentes sentem na sua pratica diária em sala de aula de atender os alunos inclusos, e a maioria desses acabam por excluir os alunos das atividades diárias em que os alunos são assistidos por metodologias de ensino que acabam não atendendo as necessidades dos alunos inclusos.

\begin{abstract}
Educar crianças com necessidades especiais juntamente com seus pares em escolas comuns é importante, não apenas para prover oportunidades de socialização e de mudar o pensamento estereotipado das pessoas sobre as limitações, mas também para ensinar o aluno a dominar habilidades e conhecimentos necessários para a vida futura dentro e fora da escola. (MENDES, p.228)
\end{abstract}

Só poderemos pensar em uma sociedade inclusiva quando a escola começar de fato promover a verdadeira inclusão.

A escola inclusiva necessita formar profissionais capacitados que se utilizem da ética para promover a formação ao aluno com deficiência que respeite seus direitos, portanto os profissionais da educação precisam estar a par dos dispositivos legais que irão nortear sua prática em sala de aula. Tendo o educador o direito de ser assistidos por profissionais que auxiliem sua pratica no atendimento da criança com deficiência.

Os docentes nunca estarão preparados para promover um atendimento aos alunos com deficiências que não tenha desafios, pois nem mesmo as melhores teorias darão ao profissional, respostas perfeitas e exatas para os problemas enfrentados no dia a dia. A verdadeira aprendizagem ocorrerá no contato com o aluno, na ação pratica em que o professor será tão aprendente como o próprio aluno. Onde buscará superar os desafios diariamente para que seu aluno seja de fato incluso. $O$ professor com aluno incluso terá a paciência de construir-se todos os dias em sala de aula. Muitas vezes irá desesperançar-se, outras entristecer-se, e até esmorecerse diante das dificuldades, mais se este for um profissional compromissado com a 
inclusão, fará de suas dificuldades, incentivos para sua superação, utilizando-se da autonomia, da criatividade, da ousadia e do desejo de querer superar as dificuldades para cada dia fazer algo melhor pelos alunos inclusos.

\begin{abstract}
Este fato é bastante interessante na medida em que a socialização é um aspecto importante para uma inclusão escolar bem-sucedida, pois a convivência dos alunos com necessidades educacionais especiais em ambientes comuns e as interações sociais que se estabelecem servem para aumentar uma variedade de habilidades comunicativas, cognitivas e sociais, bem como para proporcionar aos alunos proteção, apoio e bem-estar no grupo. (STAINBACK e STAINBACK, 1999)
\end{abstract}

Promover a inclusão é um desafio não só do educador das turmas regulares mais de toda a comunidade, fazer com que o direito da pessoa com deficiência seja respeitado é um dever de todos. A inclusão no Brasil caminha a passos lentos, pois a ausência de fiscalização das políticas públicas inclusivas contribui para que os direitos da pessoa com deficiência sejam sonegados.

Os docentes precisam adaptar suas metodologias de ensino para que a criança inclusa seja atendida no seu processo de aprendizagem, e adaptar metodologias requer conhecimento, formação, capacitação, e estas precisam ser continuas.

Em muitos municípios do estado do Pará algumas escolas que promovem a inclusão tem as salas de AEE, que buscam auxiliar o processo de ensino aprendizagem do aluno com deficiência assim como auxiliar também a pratica do professor. Em que juntos os profissionais do AEE buscam de forma integrada direcionar uma proposta pedagógica para atender as necessidades do aluno com deficiência.

A escola por muito tempo deixou de ser um espaço homogêneo, em que se mantinha um único padrão de ensino ou forma de ensinar. A necessidade de respeita a diversidade no ambiente educacional direcionou o educador a constituir uma pratica também diversificada, assim o professor necessita promover diferente tipos de atividades para atender as necessidades de seus alunos. Portanto essa ação exige que o professor seja um eterno pesquisador, um verdadeiro aprendendo do processo de ensino, para que seja ele capaz de organizar, planejar, reorganizar, avaliar, executar, criar estratégias, para promover um ensino de qualidade e que estimule o aluno a ser agente construtor de conhecimento avançando em suas potencialidades, tendo suas limitações respeitadas. 
A inclusão escolar é vista como a melhor alternativa para os alunos segregados da escola regular, já que ela: "representa um passo muito concreto e manejável que pode ser dado em nossos sistemas escolares para assegurar que todos os estudantes comecem a aprender que pertencer é um direito e não um status privilegiado que deva ser conquistado". (SASSAKI, 1997, p.18)

A inclusão garante o direito de os alunos serem assistidos como os demais sem distinção de sua deficiência dá a necessidade de a escola promover a adaptação curricular, a maioria dos professores reclamam de não estarem preparados para lidar com alunos com deficiências, até mesmo os facilitadores que são lotados junto da turma sentem dificuldades em atender pedagogicamente os alunos inclusos.

Outro fato é as lacunas existentes entre o papel do professor e do facilitado o que compete a cada um? Qual a função que devem exercer a quem cabe o processo pedagógico? Pois muitas são as dúvidas que ainda permeia na sala de aula. Muito educadores questionam se realmente seria inclusão colocar o aluno na turma regular e deixar ele sobre os cuidados do facilitador que não tem o planejamento da turma e não domina as metodologias traçadas para a turma regular.

Para que a inclusão ocorra de fato é preciso que haja esforço de toda comunidade, para que as pessoas com deficiências consigam fazer uso dos seus direitos educacionais e sociais.

Um grande problema evidenciado no espaço escolar está na ausência das políticas formativas, os instrumentos formativos nas unidades escolares ainda são muito ineficazes, pois a secretarias de educação argumentam não ter recursos suficientes para promover as formações necessárias aos profissionais da educação. A ausência dos instrumentos formativos prejudica a pratica do professor que acaba the dando diariamente com a criança inclusa, sem está devidamente preparado para essa atuação.

Os professores necessitam de acompanhamento para readaptar suas metodologias de ensino e até mesmo sua ação didática em sala de aula, afim de direcionar um melhor atendimento as pessoas com deficiência.

O educador necessita conhecer seus alunos, suas necessidades, suas limitações, só assim será capaz de promover um ensino que possibilite a inclusão. 
dois sistemas e adaptando-os às necessidades de todos os alunos; potencialização das formas de intervenção, isto é, aplicação dos sistemas consultivos e de intervenção direta em sala de aula comum por meio do ensino cooperativo; adoção de uma nova organização escolar, propondo a colaboração, o ajuste mútuo, as formas interdisciplinares e o profissionalismo docente. (DENARI, 2006, p.36)

Em pleno século XXI com tantas mudanças ocorrendo principalmente no campo da educação não há como a escola permanecer com os moldes de uma escola de 30 anos atrás. A geração é outra e tem novos anseios, comportamento diferente, necessidades diferentes. A escola necessita ser atrativa, envolver o aluno, dar a ele prazer em querer fazer parte dela. Tornando o aluno agente construtor de conhecimento. Para que as mudanças aconteçam no campo da educação o professor precisa agir com criticidade, autonomia, sendo pesquisador e inovador de sua forma de ensinar. Um professor que desperte no seu aluno o desejo pela aprendizagem. Daí a necessidade da formação continuada, das capacitações, que direcione aos docentes a capacidade de tomada de decisão e de mudança, visando ressignificar sua pratica seu pensar.

O futuro da educação inclusiva em nosso país dependerá de um esforço coletivo, que obrigará a uma revisão na postura pesquisadores, políticos, prestadores de serviços, familiares e indivíduos com necessidades educacionais especiais, a fim de trabalhar uma meta comum: a de garantir uma educação de melhor qualidade para todos. (MENDES, 2004, p.228).

Portanto direcionar politicas formativas nas unidades de ensino é uma ação necessária e urgente para que a inclusão de fato ocorra na pratica saindo do papel. A qualidade da educação inclusiva só acontecerá quando a escola começar a aplicar na pratica os dispositivos legais que dão a pessoa com deficiência sua cidadania.

\section{PRATICA PEDAGOGICA, OS DESAFIOS DO PROFESSOR COM ALUNO INCLUSO.}

Um dos maiores desafios em sala de aula nos dias atuais é a ação inclusiva. O docente encontra em sua pratica diárias inúmeros desafios para atender o aluno com deficiência, essas dificuldades advêm desde a questão estrutural, como falta de formação e capacitação aos profissionais da área, ausência de recursos adaptados, ausência de políticas públicas para promover de fato a inclusão, e principalmente a 
ausência dos centros de atendimento como as salas de AEE. Inserir a criança com deficiência através da matricula na rede regular de ensino não faz dela uma pessoa inclusa.

A lei que garante a inclusão trás as pessoas com deficiência o direito de serem assistidas por uma educação de qualidade nas turmas regulares dos demais alunos, mas também direciona a necessidade de adaptar a escola para receber essa criança.

Entramos numa época de fluidez e flexibilidade que traz implícita a necessidade de uma reflexão a respeito da maneira de como os homens fazem os mundos onde vivem, já que não os encontram prontos com uma referência permanente (MATURANA, 2002: 60).

A escola precisa ser reajustada para atender a inclusão como determina a lei, a adaptação das instituições de ensino não é um processo fácil, mas é uma ação que necessita acontecer. A escola precisa romper com seus pensamentos preconceituosos e excludentes, necessita ser um ambiente dialógico, e flexível para que através da gestão democrática consiga inserir a comunidade escola como um todo para promover a inclusão. Pensar em uma escola inclusão se faz necessário mudar, ou seja, ressignificar a forma e a maneira de ver e agir com a pessoa com deficiência.

A escola por muito tempo foi um espaço homogêneo, tendo uma única proposta de ensino para seus alunos, com suas ações tradicionais, que buscavam e em algumas vezes ainda buscam promover um ensino padronizado, que acaba por discriminar os alunos que tem maneira diferente de agir e pensar e não se encaixam nos moldes de ensino padrão.

O professor na maioria das vezes direciona-se com uma postura pedagógica também enraizada aos moldes tradicionais onde sua forma de dar aula tem um único padrão de ensino. A pratica docente necessita atender as diversidades existentes no espaço de sala de aula, cada aluno tem seu tempo de aprendizagem, sua forma particular e aprender, suas limitações. Assim o educador necessita promover uma ação pratica diferenciada buscando atender cada aluno em suas necessidades. Romper com essa postura tradicional, homogênea e excludente, não é nada fácil, pois passa por necessidade de reorganização do processo educativo, como um todo. 
A diversidade no espaço escolar advém das relações humanas em sua etnia, religião, cor de pele, dos olhos, de gênero, de origem regionais, na própria cultura e também das diferenças adquiridas, como as pessoas com deficiências, todas convivem em um mesmo espaço e buscar respeitar essa diversidade não é nada fácil.

Porem se faz necessário garantir o direito a essas pessoas, É o chamado direito à diferença; o direito de ser, sendo diferente (FERREIRA e GUIMARÃES, 2003, p. 37). As políticas públicas para a Educação inclusiva vêm garanti as pessoas com deficiência o direito de serem assistidas seja no campo social ou educacional. Portanto, a escola necessita adaptar e reorganiza seu espaço suas ações educativas, suas diretrizes curriculares, assim como ressignificar a própria pratica docente para promover a inclusão ação que requer envolvimento de todos os profissionais da educação como da própria comunidade.

\section{O PROFESSOR, A SALA DE AULA E O ALUNO INCLUSO.}

Estar em uma sala de aula com aluno incluso, é uma ação que promove bastante discursão entre os profissionais da educação, muitas são as dificuldades que os professores sentem para atender um aluno om deficiência, a falta de formação é um ponto primordial para que o professor sinta tanto dificuldade, pois as formações quando existem em algumas escolas são bem superficiais e com uma carga horaria de um ou dois dias, o docente recebe em sala de aula crianças com diferentes tipos de deficiências ou dificuldades de aprendizagem, muitas vezes esse profissional não sabe como lidar com esses alunos, Ihe falta recursos, Ihe falta espaços adaptados, acompanhamento de outros profissionais, acessibilidade.

A sociedade com um espaço múltiplo e diversificado necessita de unidades de ensino que respeito essa diversidade, já Constituição Federal de 88 afirma e determina que todos tem direito a escola pública gratuita e de qualidade, sem distinção alguma. Portanto, segundo Lindquist, "não são nossos sistemas educacionais que tem direito a certos tipos de crianças. É o sistema escolar de um país que tem que se ajustar para satisfazer as necessidades de todas as crianças". Nesse sentido direciona-se o grande desafio não só da pratica docente mais das gestões educacionais em elaborarem ações pedagógicas e educacionais que promova através de seus dispositivos legais uma educação inclusiva que atenda 
todas as crianças de acordo com suas necessidades. Portanto reconhecer a escola como um espaço diverso é possibilitar a todos os seus sujeitos o reconhecimento de suas diferenças individuais e direcione a elas uma educação que as forme no princípio da cidadania valorizando suas diferenças dando a elas o direito de se aceitarem como são.

Assim o espaço educacional assim como a sala de aula necessita estar adaptado para atender as diferenças, não cabe a criança se adaptar a escolar por ser diferente e sim a escola promover ações para ensinar as crianças respeitando suas limitações. Estabelecer através da pratica do educador ações educativas que possibilite igualdade de oportunidades e condições a todos oferecendo um ensino que promova a formação, a cidadania e a formação global dos alunos independente de suas diferenças é a finalidade de uma escola verdadeiramente inclusiva.

Para Alvarez y Soler (1998), a educação só será inclusiva se respeitarem alalguns princípios como:

$\square$ Respeito à diversidade;

$\square$ Diminuir a competitividade e promover o sentido da cooperação e participação coletiva;

$\square$ Promover um ensino de qualidade e igualdade a todos respe4itando as diferenças;

$\square$ Romper como os moldes de padronização de ensino valorizando a identidade individual de cada ser;

Promover ao aluno um ambiente colhedor onde este possa ter repostas diversificadas e não uniforme.

$\square$ Romper com a homogeneidade no ambiente escolar propondo uma educação heterogênea;

$\checkmark$ Criar um ambiente de afetividade em que seja proporcionado a todos os alunos condições de explorar seus potenciais;

Esses aspectos são fundamentais para promover uma formação inclusiva, possibilitando que todos os alunos independentes de suas condições possam aprender juntos.

A escola inclusiva, não pode segregar, excluir, separar, selecionar discriminar através de suas ações educativas, ou seja, a educação inclusiva necessita atender a todos sem qualquer tipo de distinção. 
Muitas vezes o aluno com deficiência incluso em sala de aula acaba sendo excluído pela pratica do educador, as vezes até de forma não intencional. Pois a criança fica aos cuidados de um facilitador que não tem conhecimento da pratica ou didática do professor da turma e acaba assistindo a criança somente em termo da proteção e do cuidado. Ficando assim o aluno fora do alcance da pratica pedagógica. Então questiona-se não seria esse um princípio de exclusão?

$O$ educador sente também dificuldade no sentido de adaptar suas aulas para atender as crianças com deficiência por não saber realmente como the dar, como iniciar esse processo de adaptação.

A criança é inserida no ambiente escolar mais este ambiente não está apto a atender suas necessidades e respeitar suas limitações. Os currículos escolares não são adaptados para promover um ensino inclusivo.

A escola necessita chamar pra si a responsabilidade de propor essas mudanças pra que a inclusão de fato sai dos dispositivos legais é possam ser postas em práticas em ações atitudinais por todos da comunidade escolar.

A criança com dificuldade de aprendizagem ou com deficiência acaba sendo submetida a uma ação pedagógica fracassada, quando a escola impõe um modelo único de ensino, padronizando a diretriz curricular, e as ações metodológicas, essa concepção advém de um modelo de educação uniforme e padronizado. A pratica educativa para ser inclusiva precisa ser assistida por ações metodológicas diversificadas, tendo o processor condições e espaço e acesso a recursos adaptados e apropriados para atender as necessidades de cada aluno, possibilitando a ele o direito de aprendizagem.

Na Grã-Bretanha, em 1979, através do relatório de Warnock foi conceituado o termo de pessoas com necessidades educativas especiais, chamando a atenção da sociedade para as diferenças apontadas por determinadas pessoas em sua forma de agir e aprender, ele afirma que nem uma criança ou pessoa pode ser rotulada como incapaz de aprender, ou seja, ser considerada ineducável. Sendo assim garantido a todos o direito da educação mesmo com as limitações existenciais. Daí a necessidade de repensar o discurso, "Todos somos diferentes e merecemos respeitos" acredito que o pensar no sentido da inclusão seria "Todos somos iguais e merecemos respeito as nossas diferenças" Mais uma veze chamamos a atenção que não é a criança com dificuldade de aprendizagem ou com deficiência que 
precisa se adaptar a escola e sim a escola que precisa aceitar a criança como ele é propondo condições de a aprendizagem no respeito de suas diferenças e limitações. A escola inclusiva precisa ser aberta e dinâmica aceitando a diversidade evitando uma cultura padronizada e homogênea, valorizando em suas ações curriculares o multiculturalismo que representa a comunidade local onde a escola se insere, promovendo uma formação holística que leve os alunos ao seu desenvolvimento pleno em que este seja capaz de atuar em sociedade sabendo fazer jus aos seus direitos e deveres.

Para promover uma escola inclusiva todos os profissionais da educação e da sociedade organizada devem assumir e direcionar esforços das escolas para ampliar sua capacidade de resposta à diversidade, intimidando todas as práticas excludentes e segregadoras (CARVALHO, 1998).

As unidades de ensino necessitam direcionar um olhar mais afetivo e sensível para as necessidades dos alunos com deficiências ou necessidades educativas, buscando entender e atender os interesses, características, dificuldades, apresentadas pelos alunos frente sua formação, incentivando suas potencialidades e dando a eles condições de desenvolverem na rede pública de ensino, mediante uma educação de qualidade.

\section{METODOLOGIA}

A referida pesquisa pretende realizar um trabalho investigativo partir de uma abordagem quantitativa com ênfase em um estudo exploratório e analítico sobre 0 fenômeno estudado. Que segundo, LAKATOS (2017, p. 327), o enfoque quantitativo vale-se do levantamento de dados para provar hipóteses baseadas na medida numérica. $E$ ainda, dentro deste entendimento, SAMPIERI, COLLADO E LUCIO (2013, p. 30), afirma que o enfoque quantitativo, vale-se da coleta de dados para testar hipóteses, com base na medição numérica e na análise estatística, para estabelecer padrões e comprovar teorias.

Pois, segundo GIL (2008, P. 45), as pesquisas quantitativas,

Têm como objetivo proporcionar maior familiaridade com o problema, com vistas a torná-lo mais explícito ou a constituir hipóteses. Pode-se dizer que estas pesquisas têm como objetivo principal o aprimoramento de ideias ou a descoberta de intuições. Seu planejamento é, portanto, bastante flexível, de 
modo que possibilite a consideração dos mais variados aspectos relativos ao fato estudado.

Neste entendimento, PRODANOV (2013, pag.69), afirma que,

\begin{abstract}
A pesquisa quantitativa considera que tudo pode ser quantificável, o que significa traduzir em números opiniões e informações para classificá-las e analisá-las. Requer 0 uso de recursos e de técnicas estatísticas (percentagem, média, moda, mediana, desvio-padrão, coeficiente de correlação, análise de regressão etc.).
\end{abstract}

\title{
DESENHO DE INVESTIGAÇÃO
}

Neste estudo, optou-se pela pesquisa não experimental, que segundo ALVARENGA (2012, pag. 49,50), onde se pretende investigar os fenômenos já existente no contexto educacional das escolas públicas municipais, acerca do processo de inclusão de alunos com Necessidades Educativas Especiais ou deficiências em classes comuns, a partir de uma estudo direto do pesquisador com as categorias de profissionais (gestores escolares, coordenadores pedagógicos e docentes) que estão envolvidos direta ou indiretamente com esta clientela, a fim de conhecer esta realidade, tendo em vista uma melhor compreensão de como ocorre esses processos e sua relevância para a aprendizagem desses alunos.

\section{CONSIDERAÇÕES FINAIS}

Portanto, a inclusão da pessoa com deficiência no espaço escolar é real mais a inserção não representa a inclusão de fato como dispõe os dispositivos legais para a inclusão. a escola em sua maior parte acaba sendo excludente, negando os direitos educacionais que cabe a pessoa com deficiência. Observou-se a necessidade de fiscalização das políticas públicas inclusivas, assim chama-se a atenção para que a comunidade escola como um todo se faça mais atuante para cobrar juto a secretara de educação, sua responsabilidade para que a inclusão ocorra como estabelece a lei.

Portanto, sendo o campo da educação um ambiente formador é necessário que diariamente se faça garantir o direito e a assistência ao aluno com deficiência para que sua formação seja plena, de qualidade garantindo assim sua cidadania.

Promover a integração e socialização da pessoa com deficiência com os demais alunos é dar a ela condição de se expressar interagir, integrar, conviver, partilhar, 
vivenciando com as demais pessoas um processo construtivo de troca, de afeto, de solidariedade, de autonomia e amor. Assim a inclusão precisa ser direcionada por uma gestão participativa e coletiva que envolva toda a comunidade nas ações e projetos que façam da escola um espaço realmente de inclusão, respeito aceitação das diferenças e diversidades.

\section{REFERÊNCIAS}

ALVARENGA, Estelbina. Metodologia da investigação quantitativa e qualitativa. $2^{a}$. edição. Assunção, 2014.

CARVALHO, Rosita Edler. Temas em educação especial. Rio de Janeiro: WVA, 1998.

, M.J.S.; PORTO, L.S. Portfólio Educacional: proposta alternativa de avaliação. Porto Alegre: Editora da UFRGS, 2005.

CONVENÇÃO DA GUATEMALA, de 28 de maio de 1999. Disponível em: http://www.faders.rs.gov.br/legislacao/6/29. Acesso em 20/01/2017 às 17hs.

Constituição Federal (1988),

Declaração Universal dos Direitos Humanos (1948),

Declaração Mundial de Educação para Todos (1990),

Declaração de Salamanca (1994),

Documentos que tratam da Política Nacional de Educação Especial na Perspectiva da Inclusão

(Brasil, MEC.SEESP, 2008),

Estatuto da Criança e Adolescentes (1990),

FERREIRA, Maria Elisa Caputo e GUIMARÃES, Marly. Educação Inclusiva. Rio de Janeiro: DP\&A, 2003.

GIL, Marta, Educação inclusiva: o que o professor tem a ver com isso? / Marta Gil, coordenação; texto de apresentação do Prof. Hubert Alquéres. - - São Paulo: Imprensa Oficial do Estado de São Paulo: Ashoka Brasil, 2005. "Rede SACI" ISBN 85-7060-377-0 (Imprensa Oficial).

A. C. Métodos e técnicas de pesquisa social. 6. ed. São Paulo: Atlas, 2016.

. Como elaborar projetos de pesquisa. 4. ed. São Paulo: Atlas, 2007.

HERNANDEZ, Sampieri Robert. Metodologia cientifica. México, 2013. 
LAKATOS, Eva Maria; MARCONI, Mariana de Andrade. Fundamentos de Metodologia

Científica. Ver. E ampl. São Paulo: Atlas, 2011.

Lei ํㅡ 9.394/96 que estabelece as Diretrizes e Bases da Educação Nacional, LEME, L. H. F. Recursos pedagógicos adaptados para alunos que apresentam dificuldades motoras. 2007. 23f. Monografia (Conclusão de Curso de Pós-graduação Lato Sensu - Formação de Professores em Educação Especial) - Faculdade de Filosofia e Ciências, Universidade Estadual Paulista "Júlio de Mesquita Filho", Marília, 2007.

LEME, Erika Souza, Inclusão em Educação: das políticas públicas escolar/Rio de Janeiro: UFRJ, 2011 (Dissertação - Mestrado em Educação);

MAZZOTA, Marcos J.S. Educação especial no Brasil: história e políticas públicas 6. Ed. - São Paulo: Cortez, 2011.

MANTOAN, Maria Teresa Egler, $O$ desafio das diferenças nas escolas (organizadora). 4. Ed. - Petrópolis, RJ: Vozes, 2011.

, Maria Teresa Egler. Inclusão Escolar: O que é? Por quê? Como fazer? São Paulo: Moderna, 2013.

, Maria Teresa Egler e PRIETO, Rosângela Gavioli. Inclusão escolar.

São Paulo: Summus, 2015.

MATURANA, H. \& VARELA, F. A árvore do conhecimento: as bases biológicas da compreensão humana. 2. ed. São Paulo: Palas Athena, 2002.

MENDES, E. G. Construindo um "lócus" de pesquisas sobre inclusão escolar. In: MENDES, E.G; ALMEIDA, M. A; WILLIAMS, L. C. de. Temas em educação especial: avanços recentes. São Carlos: EDUFSCAR, pp.221-230, 2004.

S. R. A Formação Continuada de Professores e o Desafio de Romper com os Modelos Padronizados. 25ํㅡㄹ Reunião da ANPED, 2002. GT 8. Disponível em www.anped.org.br. Acesso em 15/11/2006.

E. G. Deficiente mental: A construção cientifica de um conceito e a realidade educacional. Tese de Doutorado. Curso de Pós-graduação em psicologia Experimental. Universidade de São Paulo. 1995, 387 p. 19

PIOVESAN, Flávia, Direitos humanos e o direito constitucional internacional / Flávia Piovesan. - 14. Ed., rev. e atual. - São Paulo: Saraiva 2013.

Plano Nacional de Educação (2014 a 2024)

UNESCO. Arquivo aberto sobre a educação inclusiva, Paris, 2001. 
SANTOS, Jean Martins de Arruda; BAZANTE, Tânia Maria Goretti Donato; SILVA, José Jefferson. Desafios do ensino de matemática para alunos com deficiência no ensino regular. II Congresso Internacional de Educação Inclusiva, Campina GrandeParaíba, 2011.

SASSAKI, R. K. Inclusão: Construindo uma sociedade para todos. Rio de Janeiro: WVA, 1997.

STAINBACK, S; STAINBACK, W. Inclusão: um guia para educadores. Porto Alegre: Artmed, 1999. 